\title{
Alimentary canal of the lesser house fly, Fannia canicularis (Linnaeus) (Diptera: Fanniidae)
}

\author{
Yi-Ou Chen, Dong Zhang* \& Qi-Ke Wang
}

Chen, Y.-O., Zhang, D. \& Wang, Q.-K. 2013: Alimentary canal of the lesser house fly, Fannia canicularis (Linnaeus) (Diptera: Fanniidae). — Entomol. Fennica 24: 35-42.

The alimentary canal of Fannia canicularis was studied intensively for the first time, highlighting the description of morphological characteristics and providing detailed morphometric data. Two pairs of Malpighian tubules with considerably different length were found which has been rarely documented for Calyptratae flies before. Furthermore, stout cardia and sinewy crop of the samples were observed and supposed to be responsible for the energy needed to support the longtime swarming behavior of the species.

Y.-O. Chen, D. Zhang* \& Q.-K. Wang, Department of Zoology, College of Biological Sciences and Biotechnology, Beijing Forestry University, Qinghua East Road No. 35, Mailbox 162, Beijing 100083, China; *Corresponding author's e-mail:ernest8445@163.com

Received 15 July 2012, accepted 5 November 2012

\section{Introduction}

The lesser house fly, Fannia canicularis (Linnaeus, 1761) (Diptera: Fanniidae) is a ubiquitously distributed species and considered as one of the most crucial mechanical vectors of faecalborne pathogens (Grzywacz et al. 2012). The alimentary canal is the major organ system relating to the proliferation of pathogens in medical flies serving as vectors of human disease agents (Drew et al. 1983, Jordão et al. 1996, Sukontason et al. 2000, Mumcuoglu et al. 2001, Boonsriwong et al. 2007, McGauchey \& Nayduch 2009, Michalková et al. 2009, Boonsriwong et al. 2011). To date, the morphology of alimentary canal has been widely described in families of Calyptratae (Graham-Smith 1934: Calliphoridae, Lee \& Davies 1979: Muscidae, Boonsriwong et al. 2007: Calliphoridae, Sukontason et al. 2009: Calliphoridae, Roelfstra et al. 2010: Oestridae, Boonsriwong et al. 2011: Calliphoridae). How- ever, despite the abundance and medical significance of the family, such investigations are extremely obscured in Fanniidae and just limited to that by Graham-Smith (1934), in which the alimentary canal of F. canicularis was documented only superficially.

The primary aims of this article are to provide detailed morphological characteristics and measurements of the alimentary canal, to detect the distinctive features of the alimentary organs and to try to reveal the possible relations between the morphology of the alimentary canal and the living habits in the lesser house fly.

\section{Material and methods}

Adult males of $F$. canicularis were collected in Beijing, northern China, and identified using the fanniid keys of Xue and Chao (1998). The specimens were fed with a mixture of sugar and peptone (sugar: peptone $=3: 1$ ), and wet cotton 


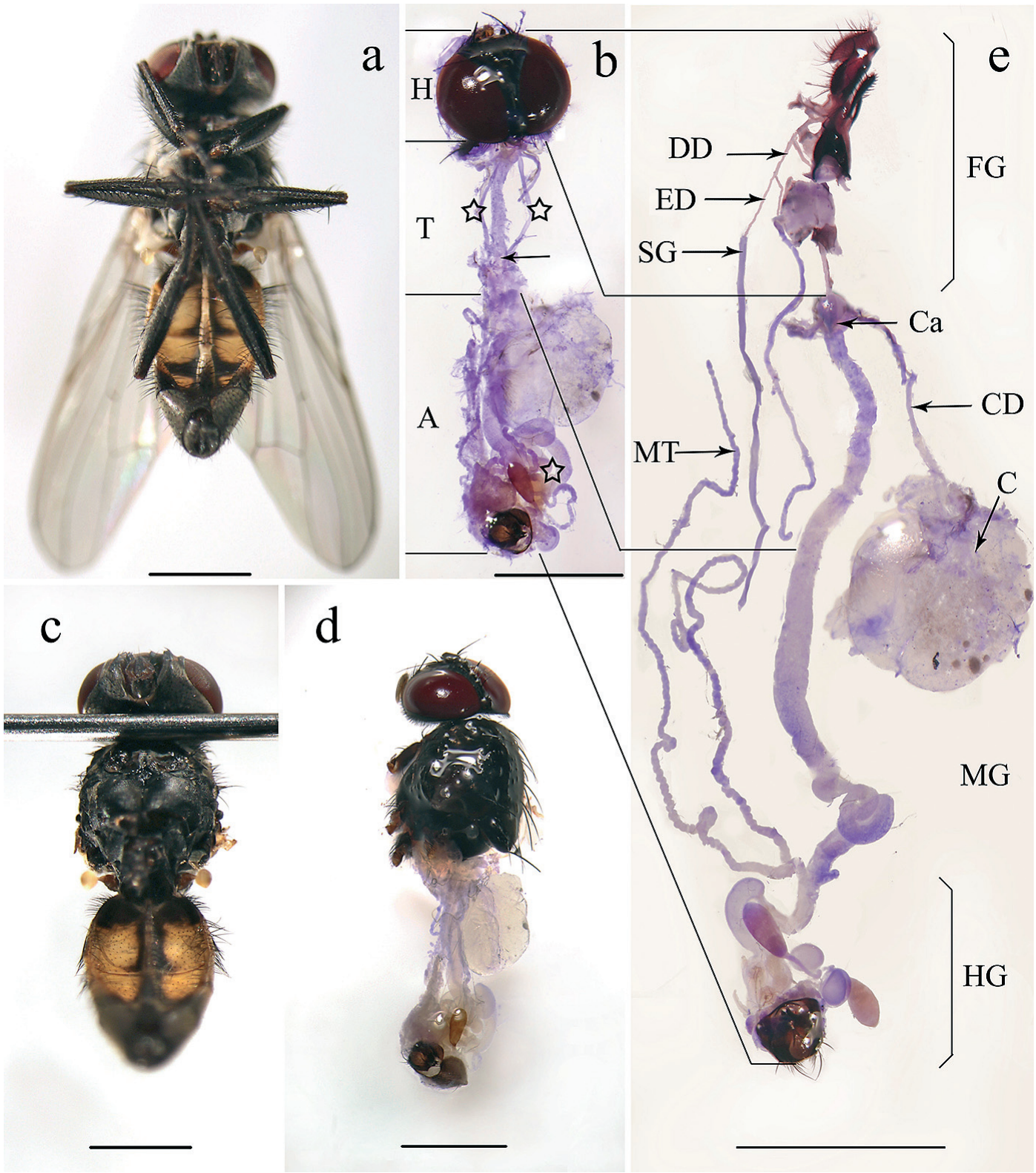

Fig. 1. Dissection of male Fannia canicularis. - a. Ventral view showing the whole body. - b. Exposed alimentary canal in thoracic region after removal of muscle tissue, showing the straight anterior ventriculus (arrow), folded posterior ventriculus (star in abdomen) and the pair of long Malpighian tubules stretching forwards the body cavity (stars in thorax). - c. Ventral view after removal of wings and legs. $-d$. Exposed posterior portion of alimentary canal after abdominal sclerites split and removed. - e. Entire alimentary canal, showing parts composing the tract. Abbreviations: A abdomen, C crop, Ca cardia, CD crop duct, DD deferent duct, ED efferent duct, FG foregut, $\mathrm{H}$ head, HG hindgut, MG midgut, MT Malpighian tubule, SG salivary gland, T thorax. Scale bars: $2,000 \mu \mathrm{m}$.

was used as water supply. Thirty specimens of male flies were killed by placing them in a freezer at $-20^{\circ} \mathrm{C}$ for $15 \mathrm{~min}$, and then soaked in near boil- ing water for a few seconds. After that each sample was dissected on a Petri dish containing phosphate buffer solution (0.1 M, pH = 7.4) (Fig. 1). 
Table 1. Measurements of internal organs of Fannia canicularis $(n=10)$.

\begin{tabular}{|c|c|c|}
\hline Part & Average & Range \\
\hline \multicolumn{3}{|l|}{ Length (mm) } \\
\hline Body & 7.41 & $6.37-8.45$ \\
\hline Oesophagus & 1.44 & $1.31-1.67$ \\
\hline Crop sac & 1.75 & $0.53-2.24$ \\
\hline Crop duct & 2.70 & $2.64-2.83$ \\
\hline Salivary glands & 4.27 & $4.16-4.41$ \\
\hline Cardia & 0.38 & $0.37-0.42$ \\
\hline Midgut & 13.17 & $10.87-15.47$ \\
\hline Long Malpighian tubule & 11.35 & $10.42-12.30$ \\
\hline Short Malpighian tubule & 1.58 & $1.40-1.76$ \\
\hline Ileum & 0.79 & $0.64-0.92$ \\
\hline Colon & 0.83 & $0.75-0.91$ \\
\hline Rectum & 0.51 & $0.43-0.59$ \\
\hline Hindgut & 3.23 & $3.12-3.46$ \\
\hline Total length of canal & 18.22 & $15.77-21.28$ \\
\hline \multicolumn{3}{|l|}{ Width (mm) } \\
\hline Oesophagus & 0.054 & $0.051-0.064$ \\
\hline Crop sac & 1.75 & $1.18-2.37$ \\
\hline Crop duct & 0.061 & $0.060-0.062$ \\
\hline Salivary glands & 0.078 & $0.068-0.088$ \\
\hline Cardia & 0.38 & $0.35-0.41$ \\
\hline Long Malpighian tubule & 0.070 & $0.059-0.080$ \\
\hline Short Malpighian tubule & 0.053 & $0.052-0.068$ \\
\hline Rectal valve & 0.15 & $0.13-0.16$ \\
\hline Dist RV-RC (mm) ${ }^{a}$ & 0.90 & $0.83-0.94$ \\
\hline \multicolumn{3}{|l|}{ Ratios } \\
\hline $\mathrm{TLAT} / \mathrm{BL}^{\mathrm{b}}$ & 2.49 & $2.48-2.52$ \\
\hline W/L of cardia ${ }^{c}$ & 1.0 & $0.92-1.12$ \\
\hline LM/TLAT ${ }^{\mathrm{d}}$ & 0.72 & $0.69-0.73$ \\
\hline
\end{tabular}

a Distance between rectal valve and rectal sac.

b Ratio of total length of the alimentary tract to body length.

c Ratio of width to length of cardia.

d Ratio of length of midgut to total length of alimentary tract.

The following operations were conducted according to the descriptions of Roelfstra et al. (2010) and Boonsriwong et al. (2011).

All specimens were individually dissected under an Olympus SZX16 stereoscopic microscope, and the alimentary canals were stained with methylrosanilinium chloride (a clinical solution, comprising methyl violet, ethanol and purified water) (Wang et al. 2009). A series of photographs of continuous sequences were taken using a Canon 500D digital camera coupled with the stereoscopic microscope and were fed into Helicon Focus for Windows to compose images with greater depth of field.

The terminology and nomenclature used to describe the morphology of the alimentary canal in this investigation follow those used by Singh and Judd (1966) and Boonsriwong et al. (2011).

\section{Results}

The alimentary canal of $F$. canicularis consists of the gut together with structures that are generally associated with it, such as salivary glands, crop and Malpighian tubules. While the Malpighian tubules are not, strictly speaking, a part of the alimentary system, they are here included in the study, because of their intimate connection with the gut. Three distinct regions that are typical in the alimentary canals of insects are observed: foregut, midgut and hindgut (Fig. 1e). Morpho- 

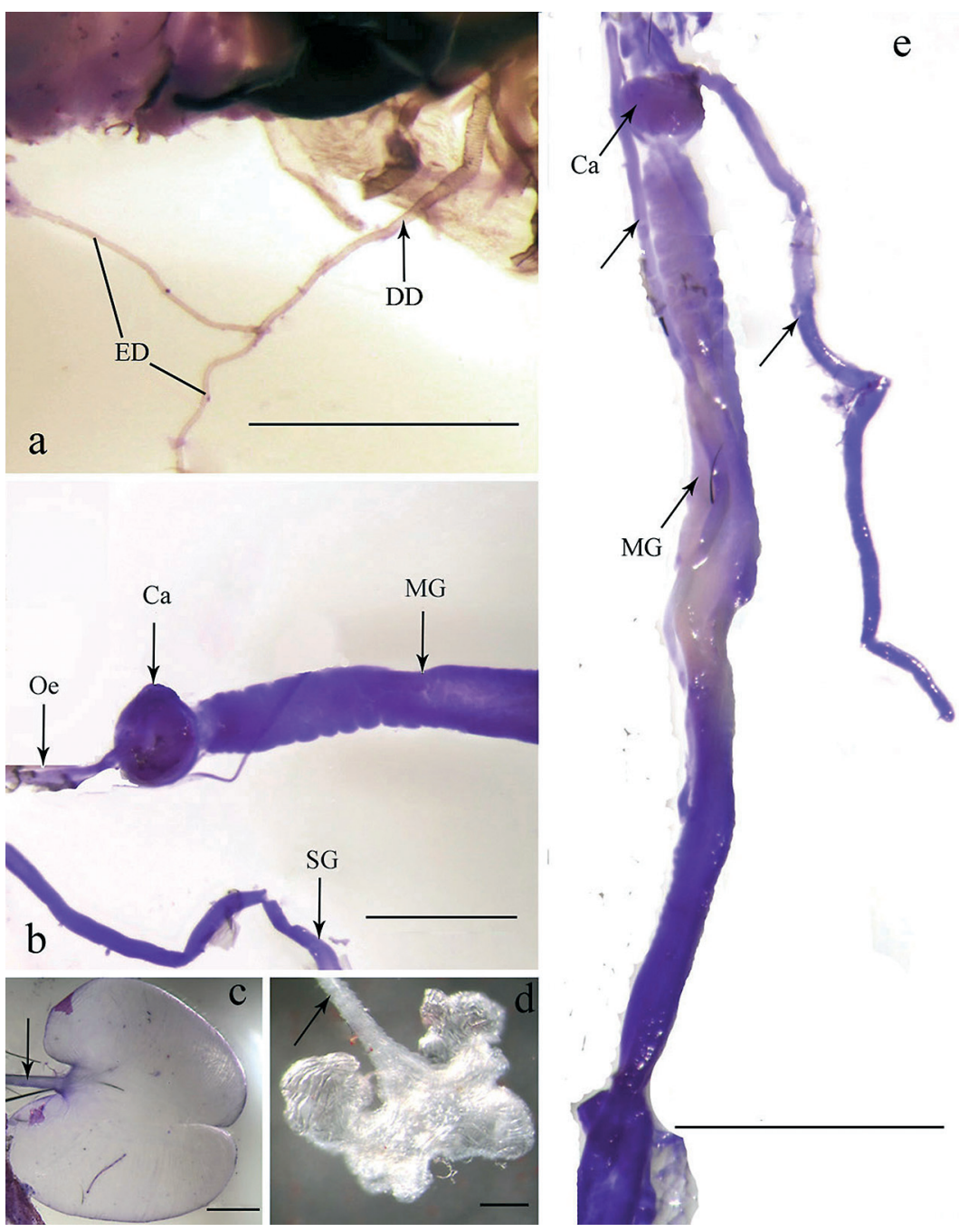

Fig. 2. Foregut of male Fannia canicularis. - a. Magnification of efferent ducts and deferent duct. - b. Oesophagus connected to cardia. - c, d. Crop duct (arrow) leading to the bilobed crop; crop storing food (c) and empty (d). - e. Pair of tubular salivary glands (arrows). Abbreviations: Ca cardia, DD deferent duct, ED efferent ducts, MG midgut, Oe oesophagus, SG salivary gland. Scale bars: 500 $\mu \mathrm{m}$ in a-c, $250 \mu \mathrm{m}$ in $\mathrm{d}$, $1,000 \mu \mathrm{m}$ in e.

logical data of the alimentary canal are examined here, as shown in Table 1.

\subsection{Foregut (Fig. 2)}

The foregut, attached with a crop and a pair of salivary glands, is subdivided into mouth, pharynx and oesophagus. It begins with the anterior mouth opening, and ends with a relatively thin and elongated oesophagus that connects to an enlarged, spherical anterior portion of the cardia (Figs. 1e, 2b).

\subsubsection{Crop}

The crop of $F$. canicularis is a lateral diverticulum of the foregut opening into the oesophagus by a narrow tube known as crop duct, before the cardia (Figs. 1e, 2b-d). The diverticulum is a bilobed sac (Fig. 2c, d) in the anterior part of the abdomen and connects to the terminus of the crop duct. The sac is extremely elastic, with numerous folds on its wall (Fig. 2d) and is capable of extreme distension when storing food (Figs. 1e, 2c).

\subsubsection{Salivary glands}

Fannia canicularis bears a pair of tubular salivary glands located laterally in the anterior body cavity, extending as far as the abdominal segment 1 (Figs. 1e, 2e). Externally, the glands are invaded by tracheae, anteriorly open into narrow efferent ducts on each side, and then the ducts join to form 

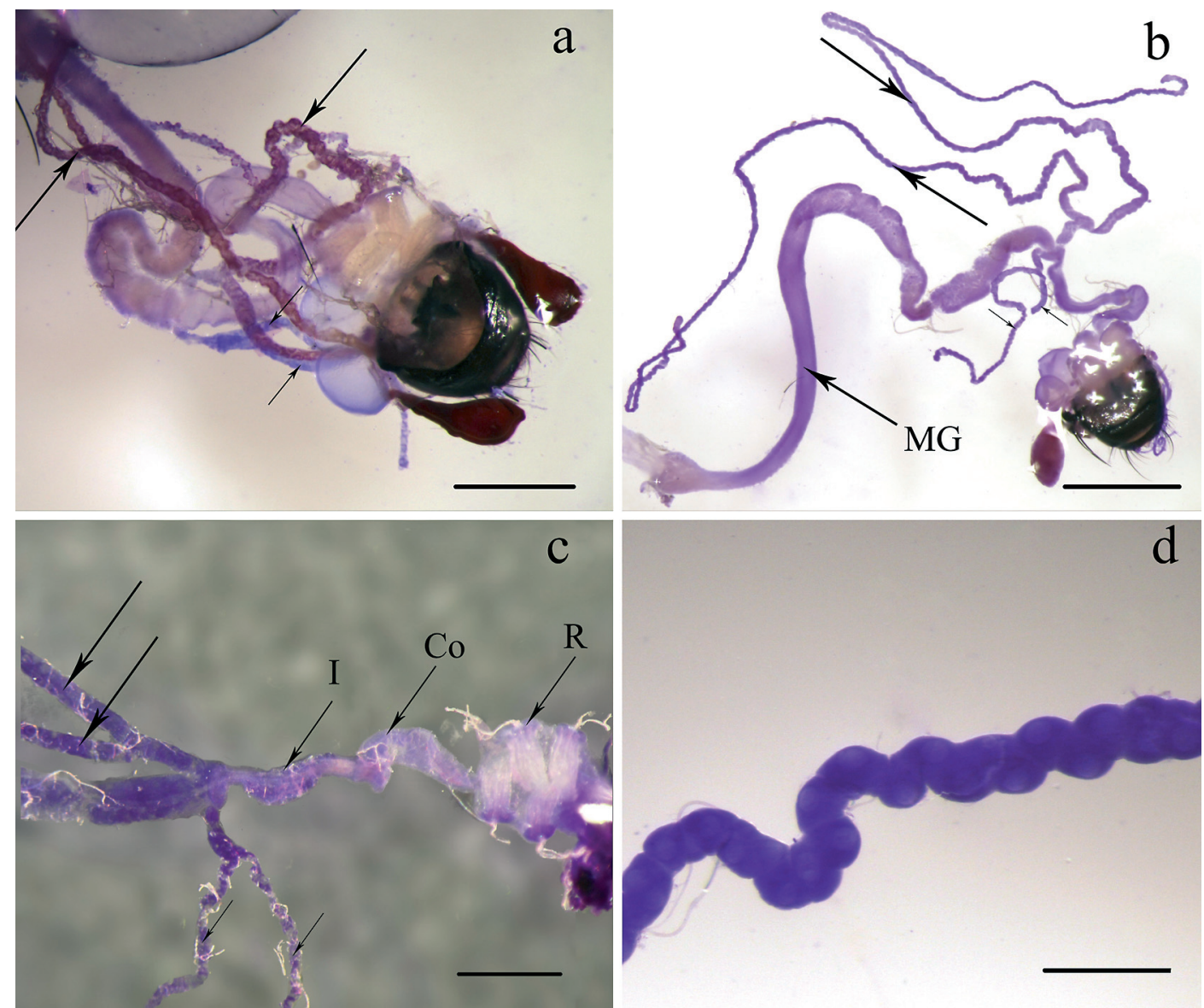

Fig. 3. Malpighian tubules of male Fannia canicularis. - a, c. Ventral view showing two long Malpighian tubules (large arrows) stretching forwards in the body cavity and two short ones (small arrows) extending backwards. - b. Long (large arrows) and short (small arrows) chains of Malpighian tubules emerging from junction of midgut and hindgut. $-\mathrm{d}$. Magnification of Malpighian tubule. Abbreviations: Co colon, I ileum, MG midgut, R rectum. Scale bars: $500 \mu \mathrm{m}$ in a and c, 1,000 $\mu \mathrm{m}$ in b, $250 \mu \mathrm{m}$ in $\mathrm{d}$.

a single median deferent duct opening into the anteroventral region inside the mouth (Fig. 2a).

\subsection{Midgut}

The midgut, composed of cardia, anterior ventriculus and posterior ventriculus (Fig. 1b), is the longest part of the alimentary canal and anteriorly delimited by cardia, posteriorly by Malpighian tubules (Fig. 1e). The cardia is a swelling ovoid structure that shows two layers (Figs. 1e, $2 \mathrm{~b}, \mathrm{e})$, with outer region connecting to the midgut and the inner one joining to the oesophagus.

\subsubsection{Anterior ventriculus}

From the posterior margin of the cardia, the anterior ventriculus takes its origin and extends the whole length of the thorax, running backwards in a straight line.

\subsubsection{Posterior ventriculus}

Following the anterior ventriculus is the highly coiled posterior ventriculus which contains several loops, and turns its end at the origin of the Malpighian tubules, as it is naturally folded together with the hindgut in the body cavity. 

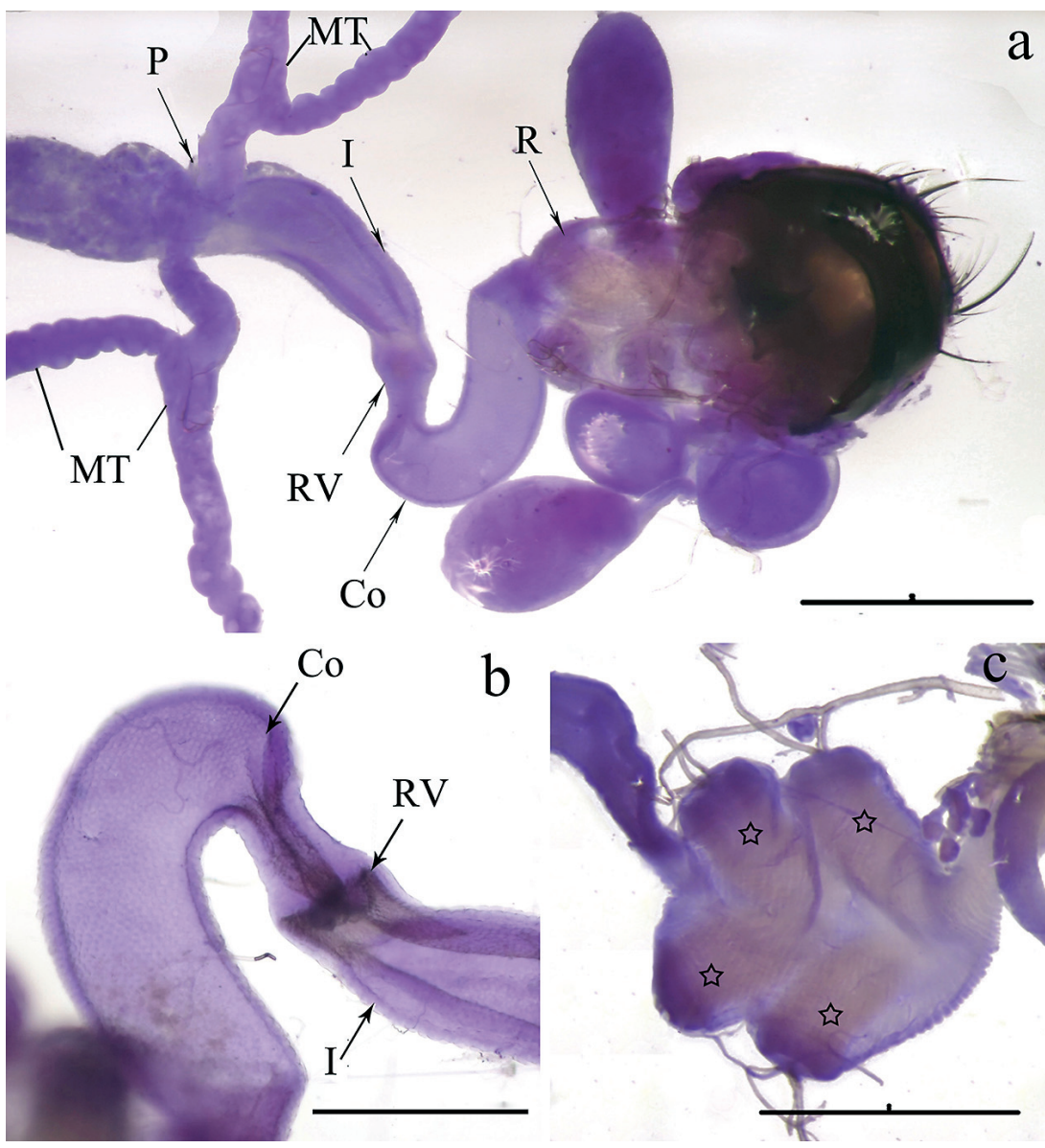

\subsection{Malpighian tubule (Fig. 3)}

The midgut is posteriorly delimited by the insertion of two Malpighian tubules, which both diverge into two pairs to give a total of four blindending Malpighian tubules (Fig. 1e, Fig. 3). The tubules are yellow in living samples, folded and asymmetric, with the longer pair stretching forwards the body cavity and the other extending backwards.

\subsection{Hindgut (Fig. 4)}

The hindgut begins from the origin of Malphigian tubules, separated by an internal invagination called rectal valve (Fig. 4b) and further divided into pylorus, ileum, colon, rectal sac, rectal papillae (four), rectum and anus from anterior to posterior (Fig. 4a, c).
Fig. 4. Hindgut of male Fannia canicularis. - a. The whole hindgut beginning from the origin of Malphigian tubules. - b. Magnification of colon, ileum and rectal valve. $-\mathrm{c}$. Magnification of four rectal papillae (stars). Abbreviations: Co colon, I ileum, MT Malphigian tubules, $\mathrm{P}$ pylorus, $\mathrm{R}$ rectum, $R V$ rectal valve. Scale bars: $500 \mu \mathrm{m}$ in a and c, $250 \mu \mathrm{m}$ in $\mathrm{b}$.

\section{Discussion}

Fannia canicularis is a common medical species of Fanniidae and noticed by its long-time swarming of male individuals at closed-in sites, such as within tree canopies or under buildings (Lewallen 1954, Anderson \& Poorbaugh 1964). The section of the alimentary canal, whole crop sac and few fat bodies are shown when the abdomen is exposed without cuticula (Fig. 1d). The small number of fat bodies decreases the body weight and is one of the reasons for the slender abdomen (Fig. 1a) which is beneficial to the swarming of this species.

Interestingly, $F$. canicularis possesses two pairs of Malpighian tubules obviously asymmetric in length (Fig. 3b). The long pair of tubes can even extend to the cardia in this species (Fig. 1b), and the ratio of the longer ones to the shorter ones is approximately 7.18 (data shown in Table 1). 
However, it is usually considered that Calyptratae flies possess two pairs of Malpighian tubules of nearly equal length (Fan 1997: Fig. 2; Boonsriwong et al. 2011: Figs. 10, 20). This considerable difference in the lengths of Malpighian tubules has been rarely mentioned in Calyptratae flies before, but it is common in at least Scolytidae (Coleoptera) (Díaz et al. 2000, 2003). The elongation of Malpighian tubules can increase their surface area which is beneficial to the excretory function (Gullan \& Cranston 2005), and make the absorption of water, salts and other valuable molecules more effective throughout the majority of the body cavity.

The present investigation indicated also that the cardia of F. canicularis is stout, and despite the extremely slender abdomen, the crop sac, which is located in the abdomen, is well developed. The cardia functions as a valve and a pump (Hewitt 1907, 1914, Patton \& Cragg 1913, Graham-Smith 1934, Gullan \& Cranston 2005), which controls the passage of food, and the crop is a temporary reservoir for food in all the feeding forms (Wigglesworth 1929, Gullan \& Cranston 2005). Thus, an ability of intense feeding behavior and an intermittent feeding habit are demonstrated. This species can suck sufficient food by the strong cardia and store it in the muscular crop when foraging. When flying, the two anterior and longer Malpighian tubules can reabsorb valuable molecules effectively, being responsible for the energy needed to support long-time swarming.

Acknowledgements. Two anonymous reviewers are greatly appreciated for their efforts in improving this paper. This study was supported by National Science Foundation of China (No. J1103516, 31201741), Programme for Colleage Student of Beijing Forestry University Scientific and Technological Innovation (No. 201214), and the Chinese Postdoctoral Science Foundation (No. 20100470009, SFG-201104059).

\section{References}

Anderson, J. R. \& Poorbaugh, J. H. 1964: Observations on the ethology and ecology of various Diptera associated with northern California poultry ranches. - Journal of Medical Entomology 1: 131-147.

Boonsriwong, W., Sukontason, K., Olson, J. K., Vogtsberger, R. C., Chaithong, U., Kuntalue, B., Ngern-klun, R., Upakut, S. \& Sukontason, K. L. 2007: Fine structu- re of the alimentary canal of the larval blow fly Chrysomya megacephala (Diptera: Calliphoridae). - Parasitology Research 100: 561-574.

Boonsriwong, W., Sukontason, K., Vogtsberger, R. C. \& Sukontason, K. L. 2011: Alimentary canal of the blow fly Chrysomya megacephala (F.) (Diptera: Calliphoridae): An emphasis on dissection and morphometry. Journal of Vector Ecology 36: 2-10.

Díaz, E., Cisneros, R. \& Zúñiga, G. 2000: Comparative anatomical and histological study of the alimentary canal of the Dendroctonus frontalis (Coleoptera: Scolytidae) complex. - Annals of the Entomological Society of America 93: 303-311.

Díaz, E., Arciniega, O., Sánchez, L., Cisneros, R. \& Zúñiga, G. 2003: Anatomical and histological comparison of the alimentary canal of Dendroctonus micans, $D$. ponderosae, D. pseudotsugae pseudotsugae, D. rufipennis, and $D$. terebrans (Coleoptera: Scolytidae). Annals of the Entomological Society of America 96: 144-152.

Drew, R. A. I., Courtice, A. C. \& Teakle, D. S. 1983: Bacteria as natural source of food for adult fruit flies (Diptera: Tephritidae). — Oecologia 60: 279-284.

Fan, Z. D. 1997: Fauna sinica. Insect. Diptera: Calliphoridae, vol.6. Science press, Beijing, 707 pp. [In Chinese.]

Graham-Smith, G. S. 1934: The alimentary canal of Calliphora erythocephala L., with special reference to its musculature and to the proventriculus, rectal valve and rectal papillae. - Parasitology 26: 176-248.

Grzywacz, A., Pape, T. \& Szpila, K. 2012: Larval morphology of the lesser housefly, Fannia canicularis. - Medical and Veterinary Entomology 26: 70-82.

Gullan, P. J. \& Cranston, P. S. 2005: The Insects: an outline of entomology, $3^{\text {rd }}$ ed. - Blackwell Science, Oxford, $528 \mathrm{pp}$.

Hewitt, C. G. 1907: The structure, development and bionomics of the house-fly, Musca domestica, Linn. - Quarterly Journal of Microscopical Science 51:395-448.

Hewitt, C. G. 1914: The housefly Musca domestica Linn. - Cambridge University Press, London, $382 \mathrm{pp}$.

Jordão, B. P., Lehane, M. J., Terra, W. R., Ribeiro, A. F. \& Ferreira, C. 1996: An immunocytochemical investigation of trypsin secretion in the midgut of the stable fly, Stomoxys calcitrans. - Insect Biochemistry and Molecular Biology 26: 445-453.

Lee, R. M. K. W. \& Davies, D. M. 1979: Feeding in the stable fly, Stomoxys calcitrans (Diptera: Muscidae). I. Destination of blood, sucrose solution and water in the alimentary canal, the effects of age on feeding, and blood digestion. - Journal of Medical Entomology 15: 541-554.

Lewallen, L. L. 1954: Biological and toxicological studies of the little house fly. - Journal of Economic Entomo$\operatorname{logy}$ 47:1137-1141.

McGauchey, J. \& Nayduch, D. 2009: Temporal and spatial fate of GFP-expressing motile and nonmotile Aeromonas hydrophila in the house fly digestive tract. - Journal of Medical Entomology 46: 123-130.

Michalková, V., Valigurová, A., Dindo, M. L. \& Vaňhara, 
J. 2009: Larval morphology and anatomy of the parasitoid Exorista larvarum (Diptera: Tachinidae), with an emphasis on cephalopharyngeal skeleton and digestive tract. - Journal of Parasitology 95: 544-554.

Mumcuoglu, K. Y., Miller, J., Mumcuoglu, M., Friger, M. \& Tarshis, M. 2001: Destruction of bacteria in the digestive tract of the maggot of Lucilia sericata (Diptera: Calliphoridae). - Journal of Medical Entomology 38: 161-166.

Patton, W. S. \& Cragg, F. W. 1913: A textbook of Medical Entomology. - Christian Literature Society for India, London, 764 pp.

Roelfstra, L., Vlimant, M., Betschart, B., Pfister, K., \& Diehl, P. A. 2010: Light and electron microscopy studies of the midgut and salivary glands of second and third instars of the horse stomach bot, Gasterophilus intestinalis. - Medical and Veterinary Entomology 24: 236-249.

Singh, S. B. \& Judd, W. W. 1966: A comparative study of the alimentary canal of adult calyptrate Diptera. Proceedings of the Entomological Society of Ontario 96: 29-80.

Sukontason, K. L., Chaiwong, T., Chaisri, U., Vogtsberger,
R. C. \& Sukontason, K. 2009: Ultrastructure of male accessory glands of Chrysomya megacephala (Fabricius) (Diptera: Calliphoridae). — Journal of Vector Ecology 34: 294-303.

Sukontason, K., Bunchoo, M., Khantawa, B., Piangjai, S., Sukontason K., Methanitikorn, R. \& Rongsriyam, Y. 2000: Mechanical carrier of bacterial enteric pathogens by Chrysomya megacephala (Diptera: Calliphoridae) in Chiang Mai, Thailand. - The Southeast Asian Journal of Tropical Medicine and Public Health 31: 157-161.

Wang, R. R., Liang, A. P. \& Webb, M. D. 2009: A new tropiduchid planthopper genus and species from China with descriptions of in copula genitalic structures (Hemiptera: Fulgoromorpha). - Systematic Entomology 34: 434-442.

Wigglesworth, V. B. 1929: Digestion in tsetse-fly: a study of structure and function. - Parasitology Cambridge 21: 288-321.

Xue, W. Q. \& Wang, M. F. 1998: Fanniidae. - In: Xue W. Q. \& Chao C. M. (eds.) Flies of China: 809-835. Liaoning Science and Technology Press, Shenyang, 1,365 pp. [In Chinese.] 